\title{
Toward a National Market System for U.S. Exchange-listed Equity Options
}

\author{
ROBERT BATTALIO, BRIAN HATCH, and ROBERT JENNINGS*
}

\begin{abstract}
In its response to the 1975 Congressional mandate to implement a national market system for financial securities, the Securities and Exchange Commission (SEC) initially exempted the option market. Recent dramatic changes in the structure of the option market prompted the SEC to revisit this issue. We examine a sample of actively traded, multiply listed equity options to ask whether this market's characteristics appear consistent with the goals of producing economically efficient transactions and facilitating "best execution." We find marked changes between June 2000, when quotes are often ignored, and January 2002, when the market more closely resembles a national market.
\end{abstract}

EQUITY OPTION TRADING CHANGED dramatically with the beginning of vigorous competition for order flow in many actively traded options during August 1999; the introduction of payment for order flow soon thereafter; and the launch of the International Securities Exchange in May 2000. Prior to these changes, many actively traded options were listed on only one exchange. For these options, there were no order routing decisions, and interactions between market participants were governed by one exchange. Most actively traded equity options now are listed on more than one options exchange, suggesting that no single exchange controls trading in these options.

In a July 2000 press release, the Securities and Exchange Commission (SEC) noted that many equity option trades occurred at prices worse than the prices apparently available at competing market centers (SEC (2000a)). This finding conflicts with the Congressional directive in the 1975 Securities Act Amendments requiring the SEC to create a national market for financial securities in which transactions are economically efficient and brokers can achieve best

\footnotetext{
*Robert Battalio is from the University of Notre Dame's Mendoza College of Business, Brian Hatch is from the University of Cincinnati's College of Business, and Robert Jennings is from Indiana University's Kelley School of Business. We thank an anonymous firm for providing the data. We also thank an anonymous referee, Amy Edwards, Richard Green (the editor), Frank Hatheway, Mike Hemler, Eugene Kandel, Paula Tkac, participants in the 2002 American Finance Association meeting, the 2001 Western Finance Association meeting, the Nasdaq-Notre Dame Microstructure Conference, and the Vanderbilt FMRC's Conference on Market Quality, and seminar participants at University of Notre Dame, Texas A\&M University, Hofstra University, and the University of Southern California finance workshops for comments on previous versions of the paper. Finally, we thank Jerry O'Connell, Compliance Director at Susquehanna International Group for his comments on the paper.
} 
execution for their customers. Given the growing influence of payment for order flow on order routing decisions in late 1999, the SEC was reluctant to rely on competition and the existing regulatory structure to guide option trading toward a national market system. Instead, in October 1999, the SEC ordered the option exchanges to develop a plan to electronically link the various market centers. The SEC ultimately approved a formal linkage plan and imposed more stringent quoting and disclosure rules on the option market (see SEC (2000b, 2000c)).

Although linkage is one approach to facilitate a national market, mandated linkage can be costly and might be failure prone. Stoll (2001) argues that regulatory mechanisms designed to link trading venues stifle competition and innovation by requiring that all markets conform to the linkage mechanism. Formal linkages also are likely to fail in the long run because no individual market has an incentive to improve or maintain the mechanism. ${ }^{1}$ If market forces, acting in response to heightened scrutiny of brokers' routing decisions, increased competition for order flow, and/or the threat of additional regulation, created a de facto national market in options, then the costs of formal linkage can be avoided. Surprisingly, there are no recent analyses of whether the equity option market evolved toward a national market as participants adjusted to the new environment. We use trade and quote data from June 2000 (a period coinciding with the SEC analysis) and January 2002 (a period just prior to the SEC setting the deadline for implementation of the linkage plan) to examine the extent to which the equity option market has become a national market system as originally envisioned by Congress. In the process, we also characterize the new option trading environment.

We begin by examining option quotes from the various market centers. Reliable and timely quotes are important to the existence of economically efficient markets and are valuable to brokers seeking best execution. Prolonged periods of crossed quotes (National Best Bid price exceeds National Best Offer price) suggest an inefficient market. For example, if Chicago is bidding $\$ 2.10$ for an option while Philadelphia is offering $\$ 2.00$ for the same option, then the parties can transact at a better price $(\$ 2.05)$ than the prices at which each indicates a willingness to trade. Alternatively, arbitragers could buy the option in Philadelphia and immediately resell it for a profit in Chicago. We find that the average sample option class ${ }^{2}$ has crossed National Best Bid and Offer (NBBO) quotes about 93 seconds of the average trading day during our first sample period, June 2000. The average cross during this sample period lasts 51 seconds and trades occur during 21 percent of the crosses. In our second sample period, January 2002, we find that the average sample option class has crossed quotes

\footnotetext{
${ }^{1}$ Stoll (2001, p. 16) notes that the Intermarket Trading System, which provides for order routing between venues trading equity securities, "is a good example of linking that has not kept pace with technology."

${ }^{2}$ The term option class refers to all options with a common underlying stock. The term option series refers to a particular option characterized by the underlying stock, option type (put or call), strike price, and expiration date. The NBBO is determined by taking the highest bid price and lowest offer price across all markets quoting the option.
} 
just 14 seconds per day (15 percent of the crossed time in June 2000). The average cross lasts 36 seconds and trades occur in about 30 percent of the crosses. Thus, to the extent that crossed markets represent locational arbitrage opportunities, we find traders apparently taking advantage of these opportunities nearly 50 percent more frequently in 2002 than in 2000 . Because the number of crosses drops between the two sample periods, our estimate of potential arbitrage profits falls by nearly 90 percent.

We examine two issues when studying execution quality. First, we document the overall level of execution quality and how it changes between our two sample periods. Second, we compare market centers. If execution quality varies across exchanges, then brokers require standardized execution quality statistics to achieve best execution for their clients (see Macey and O'Hara (1997) for a discussion of best execution). SEC (2000a) indicates that this type of execution quality information is unavailable in the equity option market. ${ }^{3}$ To determine the overall execution quality in the option market and the extent to which execution quality varies by exchange, we examine trade-through rates and effective spreads. We begin by computing trade-through rates because they represent violations of price priority and because they are a commonly used statistic in the equity option market. Trade-throughs, which occur when trades execute at prices outside of prevailing quotes, are indicative of economically inefficient trades because investors seemingly should receive better prices. For a more detailed examination of execution quality, we examine effective spreads because they consider the amount by which trade prices fall inside of or outside of the NBBO. Frequent violations of price priority and/or systematic across-exchange variation in execution quality are inconsistent with national market system objectives.

Examining small trades (a proxy for retail orders) in the sample options, our most conservative trade-through rate falls from 4.39 percent in June 2000 to 1.34 percent in January 2002. The overall, small-trade effective spread declines from about $\$ 0.22$ to less than $\$ 0.09$ between our sample periods, a 60 percent reduction. Quoted spreads fall from $\$ 0.19$ to less than $\$ 0.09$. We estimate that the cost of liquidity (trade-throughs' cost) falls by 62 percent ( 86 percent) in the 18 months from June 2000 to January 2002. Across-exchange execution quality differences exist in June 2000. Effective spreads range from 121 percent of the quoted NBBO spread in Chicago to 105 percent of the quoted spread on the American Stock Exchange. After controlling for order flow characteristics and market conditions in a multivariate setting, we find that Philadelphia's effective spread is the lowest and that the Pacific Exchange charges less for liquidity than Chicago or the American Stock Exchange. In January 2002, the

\footnotetext{
${ }^{3}$ SEC (2000a) concludes that "broker-dealers don't have adequate market execution quality information to reliably compare the quality of executions between specialist firms" in the equity option market (quote taken from the Executive Summary). Furthermore, the study notes that independent execution quality vendors cannot develop reliable execution quality reports because the exchanges do not provide them with adequate data. As of July 2002, some venues had begun to make such reports available.
} 
effective spreads on all exchanges except Chicago's are statistically indistinguishable from each other. Our results suggest that the equity option market more closely resembles a national market system in January 2002 than it did in June 2000. Our findings complement those of Hansch and Hatheway (2001), who find that their sample option classes' market execution quality improves in the year following the August 1999 move to multiple listing. They find that trade-through rates, quoted spreads, and effective spreads fall between August 1999 and the start of our sample period in June 2000.

The following section presents an overview of the structure of the equity option market during our sample period. Section II contains a description of our data. In Section III, we examine the quotes posted in the equity option market. The analysis in Section IV focuses on the execution quality available in the option market. Section V summarizes and concludes.

\section{Equity Option Market Structure}

Currently, there are five domestic equity option exchanges; the American Stock Exchange (AMEX), the Chicago Board Options Exchange (CBOE), the Pacific Exchange (PCX), the Philadelphia Stock Exchange (PHLX), and the International Securities Exchange (ISE). ${ }^{4}$ Four are floor-based hybrid markets ${ }^{5}$ and one is almost exclusively electronic. The floor-based exchanges are the AMEX, the CBOE, the PCX, and the PHLX. The ISE trades options electronically. On the floor-based exchanges, exchange-determined designated primary market makers (lead market makers on the PCX) act as specialists, trading for their own accounts, disseminating quotes, and providing liquidity. In addition to using specialists, these exchanges use registered option traders to supplement liquidity. Registered option traders trade for their own accounts, but have affirmative obligations to make markets. As noted by Mayhew (2002), these mechanisms resemble the open outcry structure for actively traded options. Order book officials maintain the limit order book.

The ISE has two types of market makers with quoting responsibilities. Each option class is assigned a primary market maker (PMM), who must provide continuous quotes and is responsible for overseeing the opening and for enforcing rules against intermarket trade-throughs. For additional liquidity, the ISE assigns up to 10 competitive market makers (CMM) in each option class. PMM and CMM trade only for their own accounts. Agency (customer) orders are entered by electronic access members who cannot enter quotes.

Each option exchange regulates market makers' quotes in normal market conditions. These rules, which are the same on each exchange, specify the

\footnotetext{
${ }^{4}$ At the time this paper is being written, the Boston Stock Exchange has proposed beginning a new electronic exchange, the Boston Options Exchange. They hope to begin trading in 2003.

${ }^{5}$ On a hybrid market, a significant percentage of trades execute electronically without intervention by floor members, but most of the volume executes manually. In our sample, between one-quarter and one-half of trades on the floor-based markets execute electronically.
} 
maximum quoted spread that market makers can post. ${ }^{6}$ Marketable orders arriving on the floor either execute with the party having the best quote or are split among all market participants on parity. In consideration of the affirmative obligations specialists undertake, each exchange gives the specialistequivalent the right to interact with a minimum percentage (typically 30 percent to 60 percent) of the public order flow routed to the exchange. These percentages, which vary both across exchange and across option class, can be a function of the exchange's market share.

The primary regulatory differences between the equity and equity option markets relate to the obligations underlying dealer quotes and the electronic linkage of exchanges. In the U.S. equity market, the firm quote rule requires dealers to trade at their quoted prices with anyone submitting an order within the quoted size. ${ }^{7}$ Although there was no SEC-imposed firm quote rule in the equity option market during our sample periods, each option exchange has an automatic execution system guaranteeing that small, retail marketable orders execute at or within posted quotes during "normal" market conditions. ${ }^{8}$ The value of this guarantee, however, depends on how frequently exchanges decide to classify market conditions as abnormal. Deciding that market conditions are abnormal also allows an exchange to violate maximum spread width rules. Further reducing the value of this guarantee is the fact that some market participants, including competing market makers and professional traders, do not have access to automatic executions for large orders. Instead, they must reveal their identities and trading interest to the market maker. For a competing market maker wishing to interact with a dealer on a floor-based system, this means transmitting orders to a broker who must manually relay this interest to the dealer on the trading floor. Professionals or away market makers wishing to tap the ISE's liquidity must identify themselves electronically. Once presented with a professional's desire to trade, a market maker can execute the order at the posted price (trade) or change his quote and not trade (fade) during our sample periods. The SEC instituted the trade-or-fade rule in the option market in 1994. The lack of a firm quote rule for all market participants, coupled with an absence of electronic inter-market linkage, is a major distinction between the regulatory environments of the option and equity markets. ${ }^{9}$

\footnotetext{
${ }^{6}$ The maximum allowable spread is nondecreasing in option price. For example, during our first sample period, the maximum quote width for options bid at between $\$ 2.00$ and $\$ 5.00$ is $\$ 3 / 8$. See Table III of DeFontnouvelle, Fishe, and Harris (2002) for a complete schedule.

${ }^{7}$ For a complete discussion of market maker obligations, see Restated ITS Plan (1997).

${ }^{8}$ The definition of small depends on the option being traded and the exchange on which one trades. For the options in our sample, the automatic execution systems guarantee at least 50 contracts during our sample periods. Although not uniform across options exchanges, abnormal market conditions often include fast or volatile market conditions, periods of time when the NBB exceeds the NBO (i.e., crossed markets), periods of time surrounding significant news stories, and communications or systems outages.

${ }^{9}$ See SEC Release No. 34-43591 for a description of the Trade or Fade Rule. The SEC instituted a firm quote rule in the equity option market on April 1, 2001. Quotes for interacting with professional traders, however, must be firm for only one contract during "normal" market conditions.
} 
Prior to January 20, 1990, SEC rules (the Allocation Plan) generally prohibited options on exchange-listed equities from trading on more than one option exchange. Options on Nasdaq securities listed after June 30, 1985, could list on multiple exchanges. Nine of the first 30 Nasdaq-security option classes traded on multiple option exchanges (see SEC Ex. Act Rel. 24,613,38). Based on this experience with multiple listings, the SEC adopted Rule 19c-5, eliminating the Allocation Plan. ${ }^{10}$ Despite the ability to trade options on multiple exchanges, most actively traded options continued to trade on one exchange. The exchanges' tepid move to multiply list options attracted the attention of the U.S. Department of Justice. Their investigation, which opened in November 1998 and culminated in a judgment in September 2000, focused on whether exchanges had implicitly agreed to not compete for trading in some options. At least partially in response to this action, in August 1999 the CBOE began trading Dell Computer options, an actively traded option class traditionally trading only on the PHLX (Wall Street Journal (1999a, 1999b)). This opened the way for a more substantive move toward multiple-listing of equity options. ${ }^{11}$ In response to the changing environment, option specialists began paying brokers for customer orders in October 1999. By December 1999, the two largest multiexchange option specialist firms were paying for order flow, and by July 2000 at least thirteen specialist firms were paying for order flow (SEC (2000a)) provides the chronology of payment for order flow in the option market). As of mid 2002, most of the major specialist firms paid for order flow.

To illustrate the effect of competition on the market centers' market share statistics, we select the 50 most actively traded single-listed equity option classes in July 1999 that continue to trade in June 2000 and January 2002 using Options Clearing Corporation data (www.optionsclearing.com). During July 1999, the CBOE enjoys a monopoly position in 27 classes, the AMEX in 11 , the PCX in 8 , and the PHLX in 4 of the 50 sample classes. (The ISE did not exist in July 1999). We check market shares for these 50 option classes during June 2000 (our first sample period) and in January 2002 (our second sample period). By June 2000 (about 1 year after the intense competition between exchanges began), the average market share for the market with the monopoly in July 1999 falls from 100 percent to 58.56 percent. Eighteen months later, in January 2002, the former monopolist's average market share is only 35.59 percent. Although former monopolists lose market share, they tend to remain dominant. By June 2000 (January 2002), the original monopolist does the largest share of trading for 42 (36) of the 50 classes. Despite an apparent first-mover advantage, we believe these statistics indicate that the forces of competition unleashed in August 1999 are real. For our illustration, monopolists lost nearly two-thirds of their market share in 28 months.

\footnotetext{
${ }^{10}$ Wang (2000) and Neal (1992) analyze this early competition between option exchanges.

${ }^{11}$ In August 1999, DeFontnouvelle, Fishe, and Harris (2002) find that 61 percent of the trading volume in equity options came from single-listed options and 68 percent of the option classes continued to be singly listed. By the end of September 1999, DeFontnouvelle, Fishe, and Harris find that single-listed options accounted for only 24 percent of total option volume.
} 
Wang (2000), DeFontouvelle, Fishe, and Harris (2002), and Mayhew (2002) illustrate that multiple listing improves execution quality. Wang examines 1993 data and contrasts the options listed on multiple exchanges after the Allocation Plan is eliminated to those options trading on a single exchange. After controlling for variables that influence spreads, she finds that spreads fall by 14 percent when an option is multiply listed. DeFontouvelle, Fishe, and Harris focus on 28 option classes moving from a single-listing environment to a multiple-listed environment in August 1999 and find that each option class enjoys a significant reduction in spreads after becoming multiply listed. Mayhew (2002) examines a long time series of CBOE options and finds that those trading on multiple exchanges have narrower spreads than those trading only in Chicago, after controlling for option price and trading volume. He finds that the difference is less for effective spreads than for quoted spreads and is less for actively traded option classes than for inactive classes.

Because traded options initially were single-listed, the option market does not have a history of intermarket linkage. Although a 1977 SEC study led to the transparent reporting of quotes and last sale information via the Option Price Reporting Authority, the SEC initially exempted the fledgling equity option market from many formal regulations. When the moratorium on new option listings expired in 1980, the SEC asked for comments on how to integrate the option market (SEC Release No. 16701). At that time, option dealers indicated that it was unreasonable to require intermarket linkage because quotes were updated manually. When Rule 19c-5 eliminated restrictions on listing and trading financial securities in April 1989, the SEC again noted the need to insure best execution across the various venues. In response, the American Stock Exchange, the CBOE, the New York Stock Exchange (which traded options at the time), and the Pacific Exchange filed a linkage plan in 1990, but it was not implemented. Authur Levitt, then SEC chairman, wrote the option exchanges early in 1999 asking for a plan proposing linkage, firm quotes, and protection against trades occurring at prices worse than quoted prices (features of the equity market). The move to extensive multiple listing of options in August 1999 added a sense of urgency to the SEC's interest in market linkage. Having not received a response to Levitt's letter, the SEC gave the option exchanges 90 days to develop such a plan (SEC Release No. 42029) on October 19, 1999. After receiving two plans in January 2000, the SEC chose one on February 24, 2000 (SEC Release Nos. 42456 and 43591). The two-phase rollout of the linkage plan began on January 31,2003 , and is to be completed in June $2003 .^{12}$

\section{Data and Descriptive Statistics}

Option exchanges report last sale and quote data via the Options Price Reporting Authority (OPRA). OPRA provides price and volume information on trades and current bids and offers in eligible securities. Trade data are to be reported in the proper sequence within 2 minutes of the trade. Trades not

${ }^{12}$ See SEC Release No. 34-43085 for a historical perspective on option market regulation. 
reported within 2 minutes are to be marked as delayed. Quote data are to be sufficiently numerous and timely to reflect the current state of the market in each security listed by an exchange. OPRA regularly operates from 7:30 a.m. to 6:00 p.m. Eastern time on any regular trading day (see SEC Release No. 34-43621). We acquire OPRA data from a market maker operating on each of the four floor-based option exchanges.

We choose two sample periods for study: June 2000 and January 2002. June 2000 is the first month of data available to us and consists of 71 actively traded option classes in which our data provider competes for orders. January 2002 is the final month of available data. Our January data contain trades and quotes for 615 option classes. Because we wish to examine the evolution of a national market system for equity options, we focus on the option classes in our data set trading on each of the four floor-based exchanges in June 2000 and on each of the five exchanges in January $2002 .{ }^{13}$ Of the option classes for which we have data in June 2000, 41 trade on each of the four floor-based exchanges and 30 of these option classes also trade on each of the five exchanges in January 2002. Data transmission problems cause us to eliminate June 2, 2000 from our sample. This leaves us with 21 trading days in June 2000 and 21 trading days in January 2002 in 30 option classes. ${ }^{14}$ Using statistics obtained from the Options Clearing Corporation, we find that our 30 sample option classes generate 27.89 percent (25.04 percent) of equity-option volume in June 2000 (January 2002).

Both quote and trade records contain the date and to-the-second time, the option class and series symbols, the exchange on which the quote or trade occurs, and a message. In addition, quotation records have bid and ask prices (associated sizes are not reported during our first sample period) and transaction records contain trade price and volume. It is common for orders arriving on a trading floor to be divided among all counterparties willing to match the best-available price. Thus, a single order often produces multiple trade records. Because execution quality typically depends on trade size (Easley and O'Hara (1987)) and because the option exchanges might not receive the same mix of large and small orders, we combine multiple executions in the same option series, executing on the same exchange at the same price at the same time with the same trade message, into a single trade. This reduces the number of trades in our sample by about 10 percent and tends to combine many of the reported one- and two-contract trades.

We require trades matched with quotes, which necessitates constructing NBBO prices from the quote records in our data. Throughout the trading day, an option series' National Best Bid (NBB) is the highest bid price from the sample exchanges. The National Best Offer (NBO) is the lowest offer. Because closing and indicative quotes are not firm, we exclude them when computing NBBO prices for an option series. We eliminate trades reported before 9:45 a.m. from our sample because option series do not trade freely during our initial

\footnotetext{
${ }^{13}$ None of the options in our data set trade (and only 0.436 percent of all equity option trades execute) on the ISE in June 2000.

${ }^{14} \mathrm{~A}$ list of the option classes in each sample is available from the authors upon request.
} 
sample period until the opening rotation is complete for all series in an option class. ${ }^{15}$ We eliminate trades reported after 3:55 p.m. because closing rotations are used for equity options on expiration day. We presume that the small number of trades reported with zero trading volume or with execution prices more than $\$ 2.50$ from the execution-time NBBO midpoint are data errors and eliminate them from our sample. Complex trades (e.g., spreads and straddles) are priced as a package, so we eliminate them from our sample. Because our data do not indicate which party initiates a trade, we cannot evaluate the execution quality of trades executed in crossed markets and must eliminate them from our sample. Finally, we eliminate trades with an execution-time NBBO benchmark having a zero bid, because the execution-time NBBO might not be an appropriate execution quality benchmark for these trades.

Panel A of Table I describes our sample selection process. Of the four exchanges in June 2000, the screens eliminate the most trades on the CBOE (19.06 percent) and the fewest on the PHLX (14.92 percent). In January 2002, the screens eliminate the most trades on the CBOE (16.94 percent) and the fewest on the ISE (9.96 percent). The CBOE has the largest market share of trades in both sample periods, although its share falls from 44 percent in June 2000 to 35 percent in January 2002. The ISE goes from not trading any of the sample options to a 19 percent market share in the 18 months between sample periods. In addition to the CBOE, the PCX also loses market share to the ISE, dropping from 24 percent of the sample trades to 16 percent.

As noted in the introduction, we measure execution quality. Easley and O'Hara (1987) suggest that large orders are more likely to be information-based than small orders. In Panel B of Table I, we show the frequency distribution of trade size by exchange. Because the algorithm we use to recombine trades might be imperfect and because each exchange's quote is valid only for retail marketable orders, we examine one-contract trades separately to isolate retail orders more confidently. We also examine the frequency of trades for between two and 50 contracts and trades for 51 or more contracts. The 50 contract cut-off is selected because all of the exchanges offer retail orders automatic executions for at least 50 contracts in June 2000. ${ }^{16}$ Across all exchanges, the fraction of one-lot trades falls from 16.2 percent in June 2000 to 12.5 percent in January 2002, while the frequency of trades for more than 50 contracts increases from 3.7 percent to 6.8 percent. Although the trade size distribution is not remarkably different across the four floor-based exchanges in either sample month, the PCX tends to have fewer large trades. There are relatively more trades for one contract and for more than 50 contracts on the ISE in January 2002 than are there on the floor-based exchanges. The differences in average trade

\footnotetext{
${ }^{15}$ Upon the opening of the options market, the order book official or specialist must conduct trading rotations that consist of calling for bids and offers from the crowd for each option series. Conversations with market professionals reveal that these rotations typically are complete before 9:45 a.m. Eastern.

${ }^{16}$ Although the automatic execution maximum increases to at least 200 contracts in many classes in our second sample period, we use the more restrictive 50-contract limit from the first sample period for our size cut-off.
} 


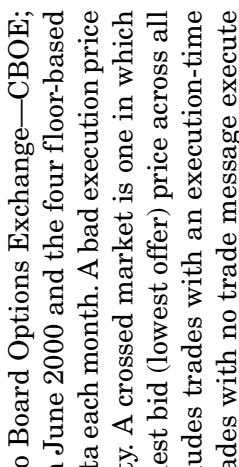

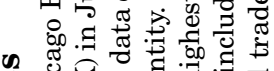

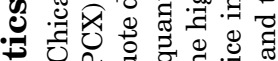

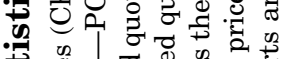

击

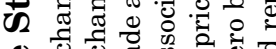

0 X

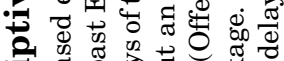

$\because$ कू

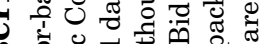

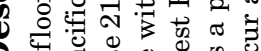

ค ॠ

๘

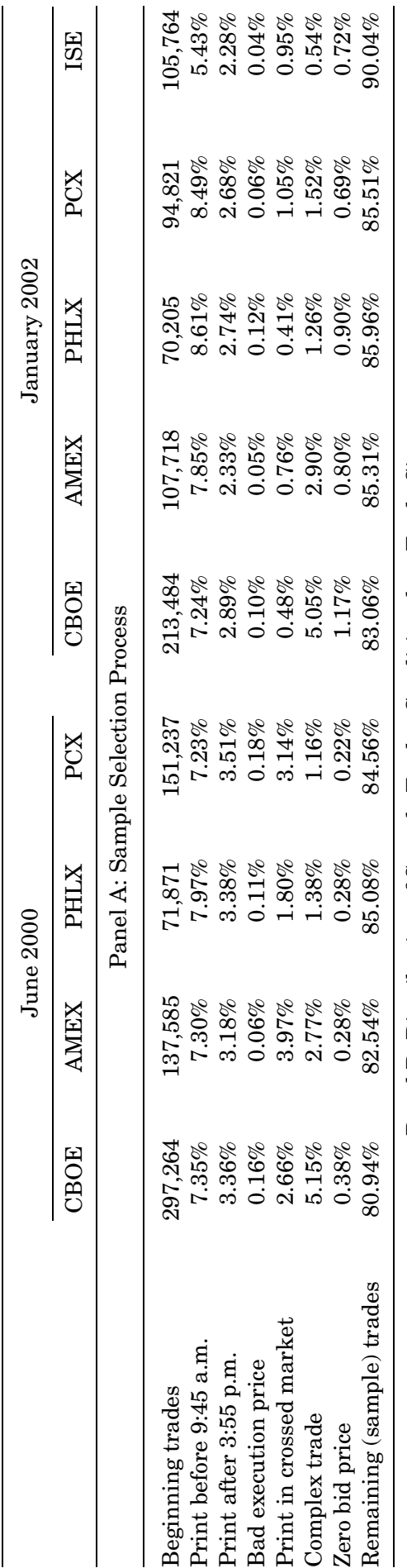

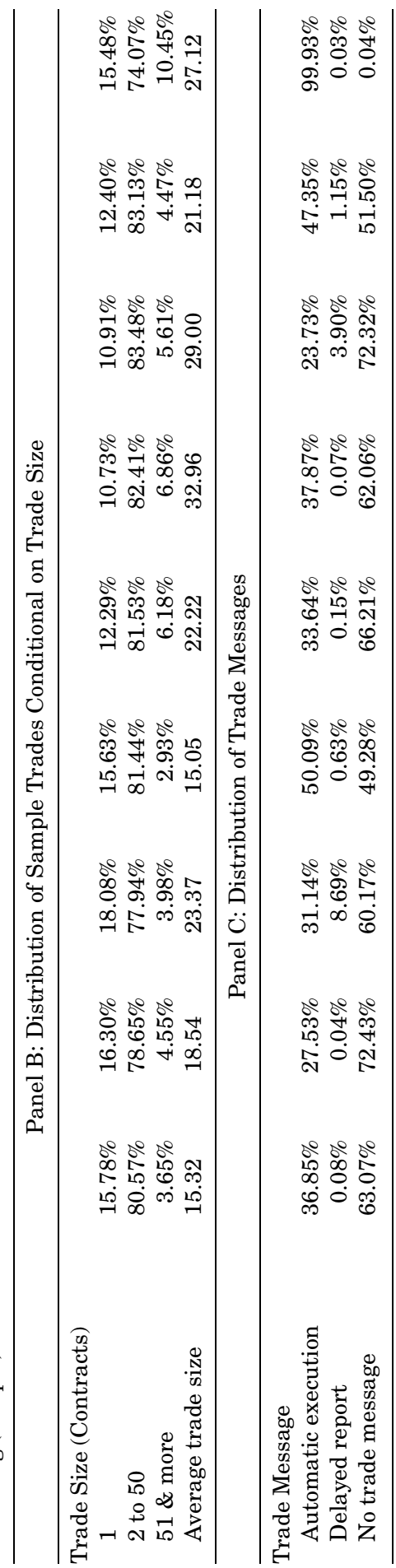


size suggest that the CBOE's market share in contracts traded, while still the largest, is less than its market share in trades. Because there are differences in the distribution of trade size in the two sample periods and across exchanges, we condition our execution quality analysis on trade size.

Panel $\mathrm{C}$ of Table I reports the messages associated with our sample trades. Our data screens leave three trade messages: (1) " " (i.e., no message); (2) "AUT" (i.e., automatically executed); and (3) "DLY" (i.e., delayed report). Trades without a message execute manually. Brokers can use the exchanges' automatic execution systems for qualifying orders, which include marketable agency orders for 50 or fewer contracts during our sample periods. Although the percent of automatic executions changes little between the sample periods in Chicago and on the PCX, they are more (less) prevalent in the second period on the AMEX (PHLX) than in the first. Nearly 100 percent of ISE's trades carry the auto-ex trade message. With the exception of the PHLX, trades rarely carry the "DLY" message. Even in Philadelphia, the frequency of delayed reports decreases substantially between June 2000 and January 2002. Overall, there are significant differences in the use of the trade messages across the exchanges. Because we do not know whether these differences reflect strategic behavior or not, we include trades with all three messages in the sample.

\section{Option Market Quotes}

Market makers' quoting behavior can facilitate efficient price discovery and help brokers achieve best execution (two objectives of the National Market System). Honoring other markets' quotes enables investors, brokers, and arbitragers to anticipate receiving the best-possible prices for their orders. Ignoring competing quotes increases the execution price risk market-order traders face and makes it more difficult for brokers to fulfill their best execution duty. In this section, we examine equity option market quotes by documenting the prevalence of locked (NBB price equals NBO price) and crossed (NBB exceeds NBO) quotes and by examining apparent arbitrage opportunities during periods in which the market is crossed.

Locked and crossed quotes represent foregone trading opportunities. Instead of locking or crossing another market's quote, market makers posting locking or crossing quotes could trade with that market (as the equity market requires). Assuming that the individual whose trading interest is represented by the locking or crossing quote wishes to trade, quoting instead of trading is not in the investor's best interest. In addition, crossed quotes represent either arbitrage opportunities or nonfirm quotes (i.e., either an arbitrager can buy and sell an option for an immediate profit or one or both sides of the market fade from the posted quote, leaving the would-be arbitrager with an incomplete trade). Panel A of Table II provides descriptive statistics of the amount of time during a trading day that our sample options experience locked or crossed markets. The time our sample options spend with locked or crossed quotes each day drops substantially between our sample periods. On average, the time in locked (crossed) markets decreases from 15.45 minutes (93.6 seconds) to 8.84 minutes 


\section{Table II}

\section{Time Spent in Locked and/or Crossed Markets}

Our sample consists of 30 equity option classes trading on all four floor-based exchanges (Chicago Board Options Exchange, American Stock Exchange, Philadelphia Stock Exchange, and Pacific Coast Exchange) in June 2000 and all five exchanges (the four floor-based exchanges plus the International Securities Exchange) in January 2002. We use 21 days of trade and quote data each month. A market for an option series is locked (crossed) when the National Best Bid equals (exceeds) the National Best Offer. The National Best Bid (Offer) price is the highest bid (lowest offer) price across all exchanges. To determine the time spent in locked (crossed) markets by an option class during our sample period, we first determine the time at which the National Best Bid for an option series equals (exceeds) its National Best Offer on each trading day. We next take the trade-weighted average across each option series in an option class to arrive at the average time spent in locked (crossed) markets on a trading day. The daily average of this statistic is the average time spent by an option class in locked (crossed) markets. The "most active option series" is the most active series in the option class each day.

\begin{tabular}{|c|c|c|c|c|}
\hline \multirow[b]{2}{*}{$\begin{array}{l}\text { Statistic } \\
(N=30)\end{array}$} & \multicolumn{2}{|c|}{ June 2000} & \multicolumn{2}{|c|}{ January 2002} \\
\hline & $\begin{array}{l}\text { Minutes in Locked } \\
\text { \& Crossed Markets }\end{array}$ & $\begin{array}{c}\text { Minutes in } \\
\text { Crossed Markets }\end{array}$ & $\begin{array}{l}\text { Minutes in Locked } \\
\& \text { Crossed Markets }\end{array}$ & $\begin{array}{c}\text { Minutes in } \\
\text { Crossed Markets }\end{array}$ \\
\hline
\end{tabular}

\begin{tabular}{|c|c|c|c|c|}
\hline \multicolumn{5}{|c|}{ Panel A. All Traded Option Series } \\
\hline Minimum & 8.24 & 0.16 & 3.35 & 0.02 \\
\hline Median & 15.33 & 1.04 & 8.87 & 0.16 \\
\hline Maximum & 30.02 & 3.88 & 16.52 & 1.14 \\
\hline Average & 17.01 & 1.56 & 9.08 & 0.24 \\
\hline$S D$ & 6.43 & 1.13 & 3.04 & 0.22 \\
\hline \multicolumn{5}{|c|}{ Panel B. Most Active Series } \\
\hline Minimum & 11.80 & 0.03 & 5.32 & 0.02 \\
\hline Median & 21.99 & 2.07 & 15.04 & 0.29 \\
\hline Maximum & 43.52 & 6.97 & 28.75 & 2.56 \\
\hline Average & 23.94 & 2.56 & 15.37 & 0.46 \\
\hline$S D$ & 8.76 & 1.90 & 5.48 & 0.52 \\
\hline
\end{tabular}

(14.4 seconds) per trading day between June 2000 and July $2002 .{ }^{17}$ This represents a 43 percent (85 percent) reduction in locked (crossed) time.

Conversations with market participants suggest that customer limit orders play a larger role in setting quotes for actively traded option series. If we are concerned about the ability of individual investors instead of professional market makers to trade at quoted prices, then we can focus on the more actively traded sample options. Panel B of Table II reports the time quotes are locked or crossed for the single option series in each class with the greatest number of trades each day. The time spent in locked or crossed markets is greater in

${ }^{17}$ To compute the average, we begin by computing the daily average time each option series spends in locked or crossed markets. To compute the average time an option class spends in locked or crossed markets, we take a weighted average across all option series in an option class where the weights are proportional to the number of trades in each series within the class. Option classes are then equally weighted to compute the reported statistic. 
the most actively traded option series than in the overall sample (suggesting that individual investors might be disadvantaged by lost trading opportunities). However, this time also diminishes substantially between the two sample periods. The time actively traded options spend in locked (crossed) markets decreases by 30 percent (72 percent) between June 2000 and July 2002.

Crossed quotes are particularly interesting because they represent apparent arbitrage opportunities. Table II's statistics suggest that the average time that arbitrage opportunities exist in the listed equity option market decreases dramatically between June 2000 and January 2002. In Table III, we provide descriptive statistics regarding the trading activity during the time that our sample options' quotes are crossed.

The median cross duration is 51 seconds in June 2000 and 36 seconds in January 2002 for our sample option classes. Consistent with the fact that the time the average option class spends in a crossed market during the average day decreases (Table II), we find that the number of crossed markets declines from 69,200 in June 2000 to 9,451 in January 2002. This represents an 86 percent

\section{Table III \\ Detailed Analysis of Crossed Market Quotes}

Our sample consists of 30 equity option classes trading on all four floor-based exchanges (Chicago Board Options Exchange, American Stock Exchange, Philadelphia Stock Exchange, and Pacific Coast Exchange) in June 2000 and on all five exchanges (the four floor-based exchanges plus the International Securities Exchange) in January 2002. We use 21 days of trade and quote data each month. A cross is defined as a situation in which the National Best Bid (NBB) price exceeds the National Best Offer (NBO) price. The NBB is the highest execution-time bid price across the exchanges. The NBO is the lowest execution-time offer price across the exchanges. We define 161 occasions in which the market is crossed by more than $\$ 2.50$ as data errors and eliminate them from the sample. The number of crosses refers to the number of times an option series belonging to one of the 30 sample option classes is crossed for the specified time category. Percent with trade(s) is the percentage of periods when the market is crossed with one or more trades reported during the cross. To determine the average value of a cross, we determine the maximum amount by which the market is crossed for each crossed market observation in the specified time category and then compute the average of this amount. For example, consider a series whose quotes are crossed for 10 consecutive seconds. If the NBB exceeds the NBO by $\$ 0.10$ for the first 5 seconds of the cross and the NBB exceeds the NBO by $\$ 0.05$ for the remaining five seconds of the cross, the maximum amount of this cross is $\$ 0.10$. Thus, $\$ 0.10$ is included in the average amount of the cross and $\$ 0.05$ is not.

\begin{tabular}{lrrrrrrr}
\hline & \multicolumn{3}{c}{ June 2000 } & & \multicolumn{3}{c}{ January 2002 } \\
\cline { 2 - 5 } \cline { 7 - 8 } $\begin{array}{l}\text { Duration of Cross } \\
\text { (Seconds) }\end{array}$ & $\begin{array}{c}\text { No. of } \\
\text { Crosses }\end{array}$ & $\begin{array}{c}\text { \% with } \\
\text { Trade(s) }\end{array}$ & $\begin{array}{c}\text { Average Value } \\
\text { of Cross }\end{array}$ & & $\begin{array}{c}\text { No. of } \\
\text { Crosses }\end{array}$ & $\begin{array}{c}\text { \% with } \\
\text { Trade(s) }\end{array}$ & $\begin{array}{c}\text { Average Value } \\
\text { of Cross }\end{array}$ \\
\hline 0 & 2,591 & 0.00 & $\$ 0.1251$ & & 354 & 0.00 & $\$ 0.0869$ \\
1 to 5 & 18,671 & 4.99 & $\$ 0.1404$ & & 2,900 & 15.83 & $\$ 0.1188$ \\
6 to 15 & 13,608 & 19.30 & $\$ 0.1462$ & & 2,433 & 31.40 & $\$ 0.1072$ \\
16 to 30 & 9,999 & 30.11 & $\$ 0.1334$ & & 1,631 & 43.23 & $\$ 0.0816$ \\
31 to 90 & 14,621 & 33.92 & $\$ 0.1316$ & & 1,533 & 47.68 & $\$ 0.0929$ \\
91 \& greater & 9,710 & 35.38 & $\$ 0.1356$ & & 600 & 39.50 & $\$ 0.1249$ \\
All & 69,200 & 21.62 & $\$ 0.1374$ & & 9,451 & 30.64 & $\$ 0.1044$ \\
\hline
\end{tabular}


reduction in these potential arbitrage opportunities. In Panel A, we document that the fraction of crossed markets in which a trade occurs increases from 21.6 percent to over 30 percent. The trading frequency increases for all positive duration categories. The apparent increased effort to arbitrage the crossed market (or market maker responsiveness to others' quotes) occurs despite the fact that the average amount by which the NBB price exceeds the NBO price (i.e., the potential arbitrage profit) falls from $\$ 0.1374$ to $\$ 0.1044$ between the two sample periods. This is consistent with market makers becoming more responsive to other markets' quotes and/or more active arbitrage.

Information in Table III allows us to estimate the potential revenue from arbitrage activities for our sample options. Assume that quotes are firm for only a one-lot trade. Suppose a trader's technology requires 91 seconds to submit the pair of orders implied to arbitrage a crossed quote. This suggests that the trader could arbitrage the 9,710 (600) crosses in June 2000 (January 2002) lasting 91 seconds or more. These crosses are worth an average of $\$ 0.1356$ (\$0.1249) per share each in our first (second) sample period. This provides the one-lot arbitrager $\$ 131,700(=9,710 \times \$ 0.1356 \times 100)$ in June 2000 and $\$ 7,500(=600 \times \$ 0.1249 \times 100)$ in January 2002 . If the trader improves the technology so that he can conduct the arbitrage trade within 31 seconds, then the trader potentially can take advantage of all the crosses lasting for at least 31 seconds. That would be $24,331(=9,710+14,621)$ trades in June 2000 and $2,133(=600+1,533)$ trades in January 2002. Potential profits for one-lot trades from this technology are $\$ 324,100$ in our first sample period and $\$ 21,700$ in the second. If the trader could improve the technology to trade a one-lot for all crosses lasting 1 second or more, then her potential profits are $\$ 918,500$ in June 2000 and $\$ 95,600$ in January 2002. Our estimates suggest a decrease of nearly 90 percent in apparent arbitrage profits between the sample periods. ${ }^{18}$

Two national market system objectives are economically efficient execution of security trades and practicability of brokers obtaining "best execution" for their customers. Locked quotes suggest that two parties who could trade do not do so, and crossed quotes suggest potential arbitrage. Neither situation seems consistent with an economically efficient market. Furthermore, because exchanges typically do not provide automatic executions in crossed markets, investors face more execution-price risk when markets are crossed than with functioning automatic execution systems. Our evidence suggests that the option market is substantially more efficient in January 2002 than in June 2000. The average time spent in crossed markets decreases dramatically between our two sample periods and nearly 90 percent of apparent arbitrage profits disappear.

\section{Execution Quality}

The onset of active competition for market share in actively traded option classes changed the landscape in the equity option market. With as many as

\footnotetext{
${ }^{18}$ The one-lot assumption is arbitrary, but is consistent with the fact that automatic execution systems do not operate during crossed markets. The assumption does not affect the percentage reduction in apparent arbitrage opportunities.
} 
five option exchanges trading certain option classes, the SEC (SEC Release No. 34-43591, page 75440) notes that brokers are increasingly "required to regularly and rigorously evaluate the execution quality available at each options exchange." In this section, we examine execution prices relative to executiontime quote benchmarks to determine whether the equity option market evolved toward a national market system. We begin by analyzing trade-throughs. A trade-through occurs when a trade fills at a price outside of the benchmark NBBO (i.e., at a price that is higher than the National Best Offer price or lower than the National Best Bid price). ${ }^{19}$ Large trade-through rates are inconsistent with a national market system because a trade-through represents a violation of price priority. Evidence of significant trade-through rates in January 2002 might suggest a role for SEC-imposed linkage.

We conclude this section by analyzing effective spreads. The effective halfspread is the absolute difference between the trade price and the benchmark NBBO spread's midpoint. The effective spread, computed by doubling the effective half-spread, is an estimate of liquidity costs of a round-trip trade. As noted earlier, in June 2000, most brokers made routing decisions without reliable execution-quality data. By January 2002, most large brokers were producing internal execution-quality reports to guide order-routing decisions, and several brokers were using "smart" routing algorithms to route their orders on an order-by-order basis to different execution venues conditional on prevailing market conditions and recent execution quality. We examine effective spreads for each of the option exchanges in June 2000 and in January 2002 to determine the extent to which the equity option market has evolved into a national market. Evidence of systematic variation in effective spreads in January 2002 might suggest that at least some brokers either cannot or will not fulfill their fiduciary obligation to obtain best execution for equity option orders.

\section{A. Trade-Throughs}

We report conditional trade-through rates in Table IV in the row labeled "vs. NBBO." Given the variation in the distribution of trade sizes across exchanges (see Panel B of Table I), in Panel A we provide execution quality statistics conditional on trade size and exchange. We report results for automatic executions in Panel B since the quote benchmark should be more accurate for these trades.

Overall, 11.09 percent of all trades (3.52 percent of automatic executions) in the sample option classes are trade-throughs relative to the NBBO in our first sample period. Thus, for one trade in nine during June 2000, it appears that a better price is available on another venue when the trade prints. Eighteen months later, the overall (auto-ex) trade-through rate falls to 3.74 percent (1.31 percent), a decline of 65 percent (63 percent). Easley and O'Hara (1987) suggest that larger trades are more likely to be informed than smaller trades. All things being equal, if adverse selection costs are higher for large trades,

\footnotetext{
${ }^{19}$ Hansch and Hatheway (2001) conclude that execution quality studies using a NBBO constructed using our methodology should be reliable.
} 


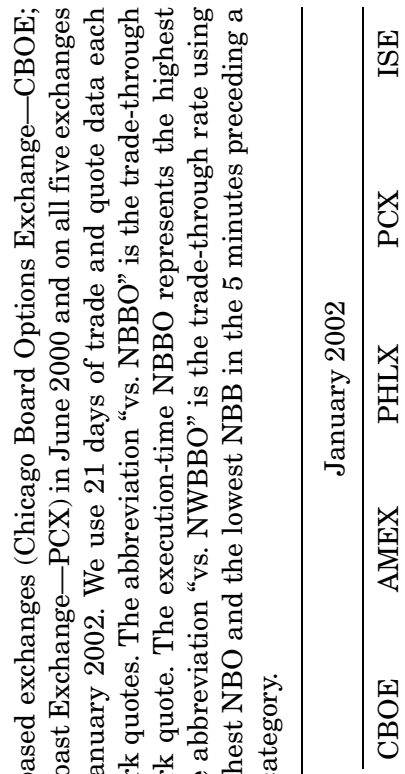

2 ช 00 ส

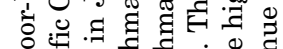
स्ष 击

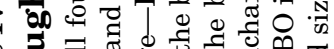
?

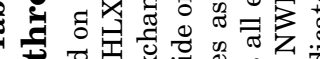

क्ष उ.

ह 品 (x)

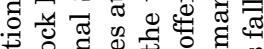
各诂.

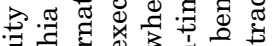

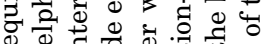
व उี

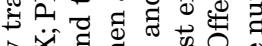
B.

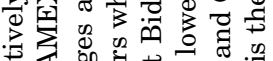
ष ○

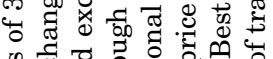

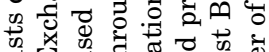
.

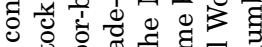

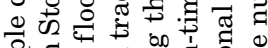

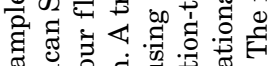

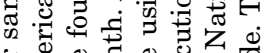

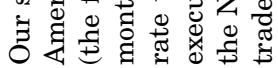

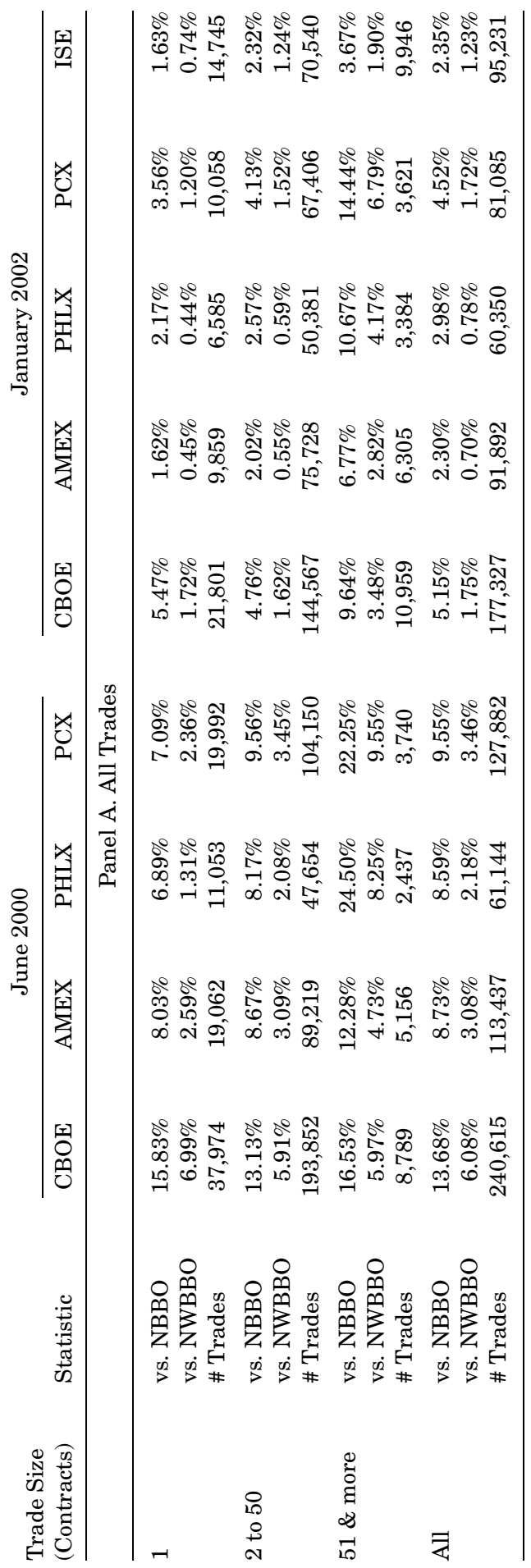




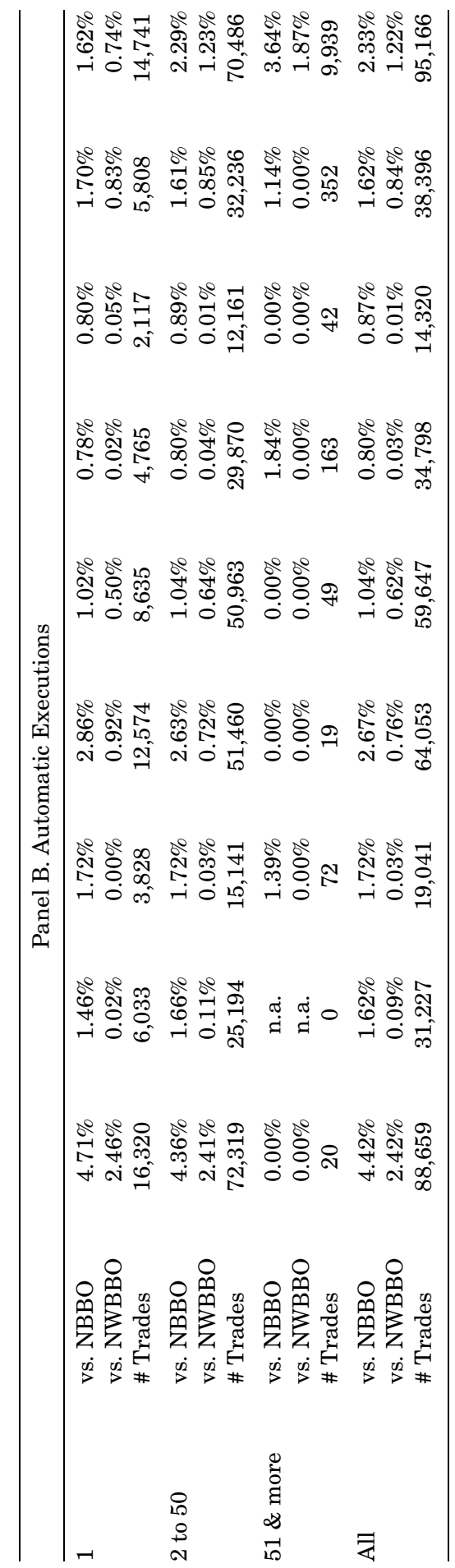


then one might expect execution quality statistics for small trades to be better than comparable statistics for large trades. Consistent with this hypothesis, trade-through rates are monotonically increasing in trade size everywhere but on the CBOE.

Trade-through rates vary across exchanges. A nonparametric difference in proportions test finds that the CBOE's overall trade-through rate exceeds the trade-through rates on each of the other exchanges at the 0.01 level in our first sample period. The AMEX and the PHLX have the lowest trade-through rate in June 2000. Although the overall trade-through rates fall between the two sample periods, the CBOE retains the distinction of having the highest average overall trade-through rate of the sample exchanges in January 2002. The AMEX's and ISE's trade-through rates are the lowest during January 2002. The CBOE's large trades enjoy execution quality that is more comparable to the industry-average execution quality.

If manual executions are regularly reported with delay, then referencing a contemporaneous quote might bias our estimated trade-through rate upward. To address this issue, we compute trade-through rates using a lagged quote benchmark. We compute this quote benchmark by finding the highest NBO and the lowest NBB observed in the 5-minute interval prior to the trade (i.e., we construct a national worst best bid and offer). Consider a trade reported at 10:43:26 a.m. as an example. We look backward through our quote data from 10:43:26 a.m. through 10:38:27 a.m. and determine the largest NBO and the smallest NBB observed during that 5-minute interval. Call those numbers $\mathrm{NBB}_{\mathrm{MIN}}$ and $\mathrm{NBO}_{\mathrm{MAX}}$. In this more conservative approach, a trade is classified as a trade-through only if the trade price falls outside of the range $\mathrm{NBB}_{\mathrm{MIN}}$ to $\mathrm{NBO}_{\text {MAX. }}$

We report trade-throughs with respect to this benchmark in the row labeled NWBBO in Table IV. A 5-minute window nearly eliminates trade-throughs for trades executing automatically during the second sample period, and it reduces the overall trade-through rate from 3.75 percent to 1.34 percent. For a basis of comparison to equities, consider Peterson and Sirri (2002), who examine system order data around the change in tick size on the New York Stock Exchange (NYSE) from $\$ 1 / 8$ to $\$ 1 / 16$. For the largest capitalization stocks in their sample, they document a trade-through rate of 2.9 percent when the tick size is $\$ 0.125$ and a trade-through rate of 7.0 percent when the tick size is $\$ 0.0625$. While these results are not directly comparable to our results because equity options trade in increments of $\$ 0.05$ and $\$ 0.10$, they do suggest that trade-through rates in the January 2002 equity option trading environment are no worse than tradethrough rates for actively traded NYSE-listed securities. If the goal of linkage is to reduce violations of price priority to a level comparable with the listed equity market, then Peterson and Sirri's results suggest that SEC-mandated linkage is unnecessary. ${ }^{20}$

\footnotetext{
${ }^{20}$ Exchanges legislate against trading through their own quotes, and our data suggest that these rules are rarely violated.
} 


\section{B. Effective Spreads}

Although the trade-throughs documented in the prior section suggest differences in liquidity costs across the sample exchanges, it is difficult to assess the economic importance of these differences knowing only the trade-through rate. By expressing the cost of liquidity as the distance between the trade's price and the midpoint of the trade-time NBBO (times two), we can assess the economic significance of our earlier results for round-trip trades. Table V presents effective and quoted spreads.

We average effective spreads by equally weighting each trade's effective spread. The average quoted spread equally weights the NBBO prevailing when each trade is reported. An effective spread exceeding the quoted spread implies that the average trade price is outside of the benchmark NBBO, and an effective spread less than the quoted spread implies that the average trade occurs inside of the benchmark NBBO. Because the NBBO varies over time, we also report the ratio of the average effective spread to the average execution-time NBBO. ${ }^{21}$ Without exception, overall effective spreads exceed quoted spreads in June 2000, implying that the average execution price is worse than the quoted price. In our second sample period, trade prices are on average roughly equal to quoted prices. For January 2002, the AMEX and the PHLX effective spreads are less than the quoted spreads, suggesting that the typical trade price is better than the quoted price on those two exchanges. The effective spreads on the CBOE, PCX, and ISE, although greater than the relevant quoted spreads, are much smaller in January 2002 than they are in June 2000. For example, the effective-to-quoted-spread ratio on the CBOE falls from 1.21 to 1.04 between June 2000 and January 2002. This suggests that execution quality improves between our two sample periods.

There are differences in the average liquidity cost among exchanges. Relative to the execution-time quoted spreads, the PHLX and AMEX provide lower liquidity costs than the other exchanges in each sample period. Consistent with the trade-through analysis, the CBOE has the most expensive liquidity (relative to quotes) in June 2000 and the PCX and the CBOE offer the most expensive liquidity in January 2002. The variation in execution-time NBBOs across markets suggests that the mix of orders (either the specific sample options in the order flow and/or the timing of the orders) in the sample option classes varies across exchanges.

Figure 1 illustrates how the distribution of the ratio of the effective-to-quoted spread changes for those trades executed when the NBO exceeds the NBB. A ratio of zero represents a trade at the NBBO midpoint. If the ratio is between zero and unity, then the trade occurs at a price between the NBBO midpoint and the relevant quote. A ratio of 1.0 implies a trade at the relevant quoted price and a ratio greater than 1.0 suggests a trade at a price worse than the relevant quote.

\footnotetext{
${ }^{21}$ One reason quoted spreads might have fallen between sample periods is the marginal reduction in the minimum price variation (from $\$ 0.0625$ to $\$ 0.05$ or from $\$ 0.125$ to $\$ 0.10$ ) occurring in April 2001.
} 


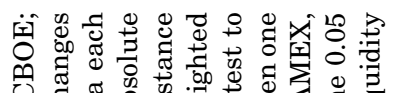

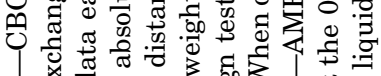

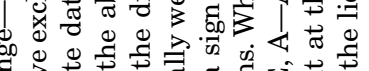

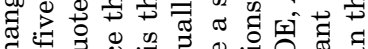

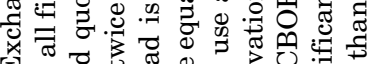

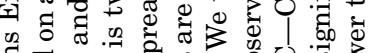

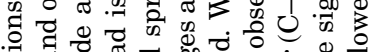

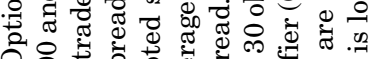
0 贾

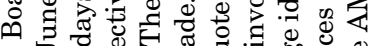

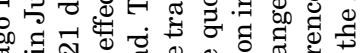

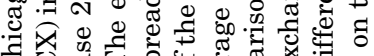

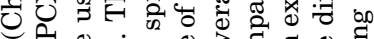

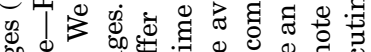
政

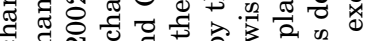
ब. क्ष 政 类 की 인

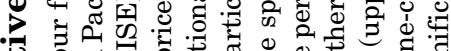
웅

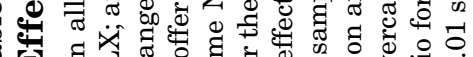

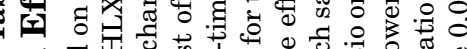

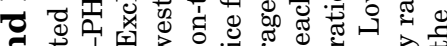
ส उ w

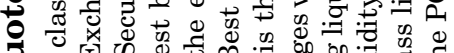
원 2 क 등 영 in क्ष

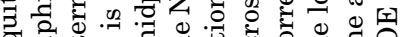
政 을 굴 藏范 ه

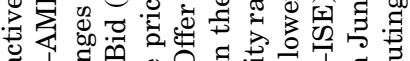
४ व

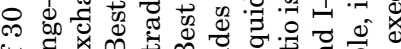
का क

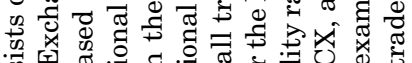

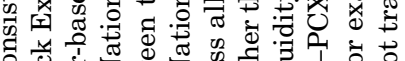

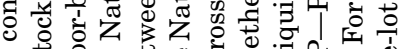

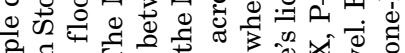

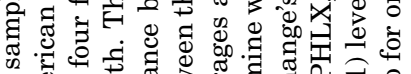

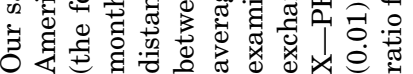

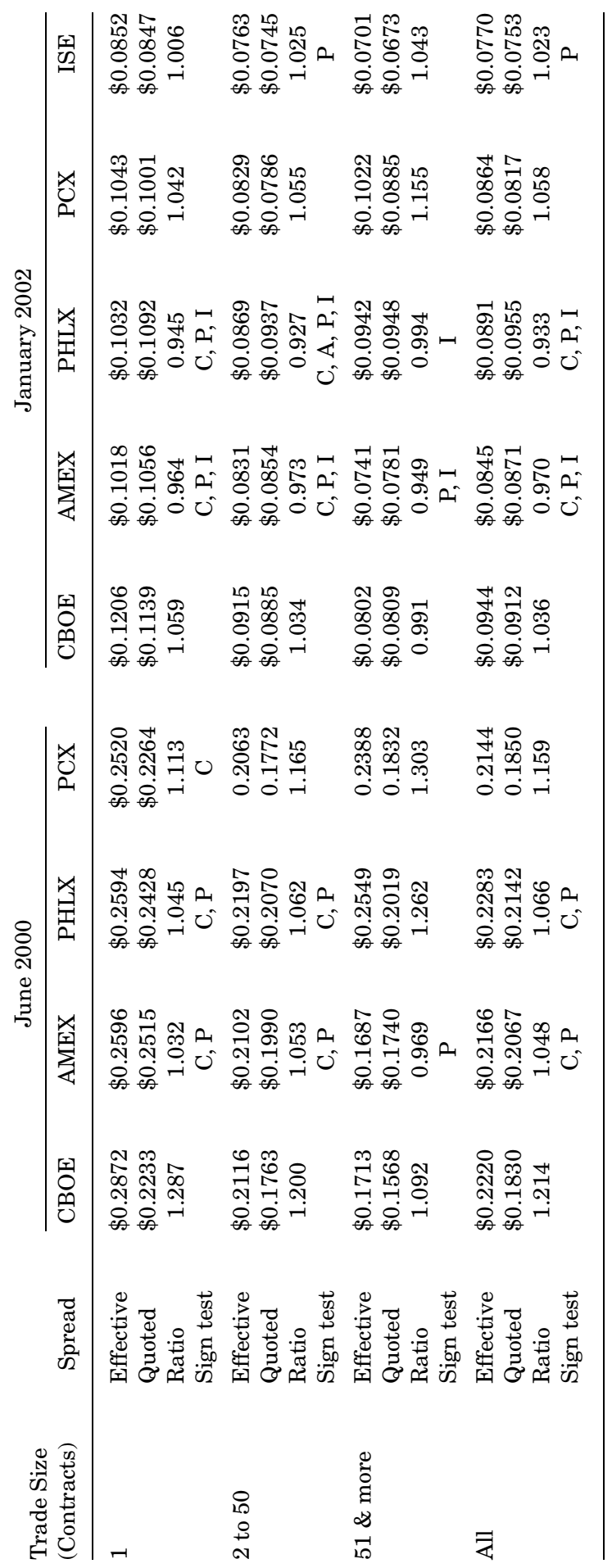




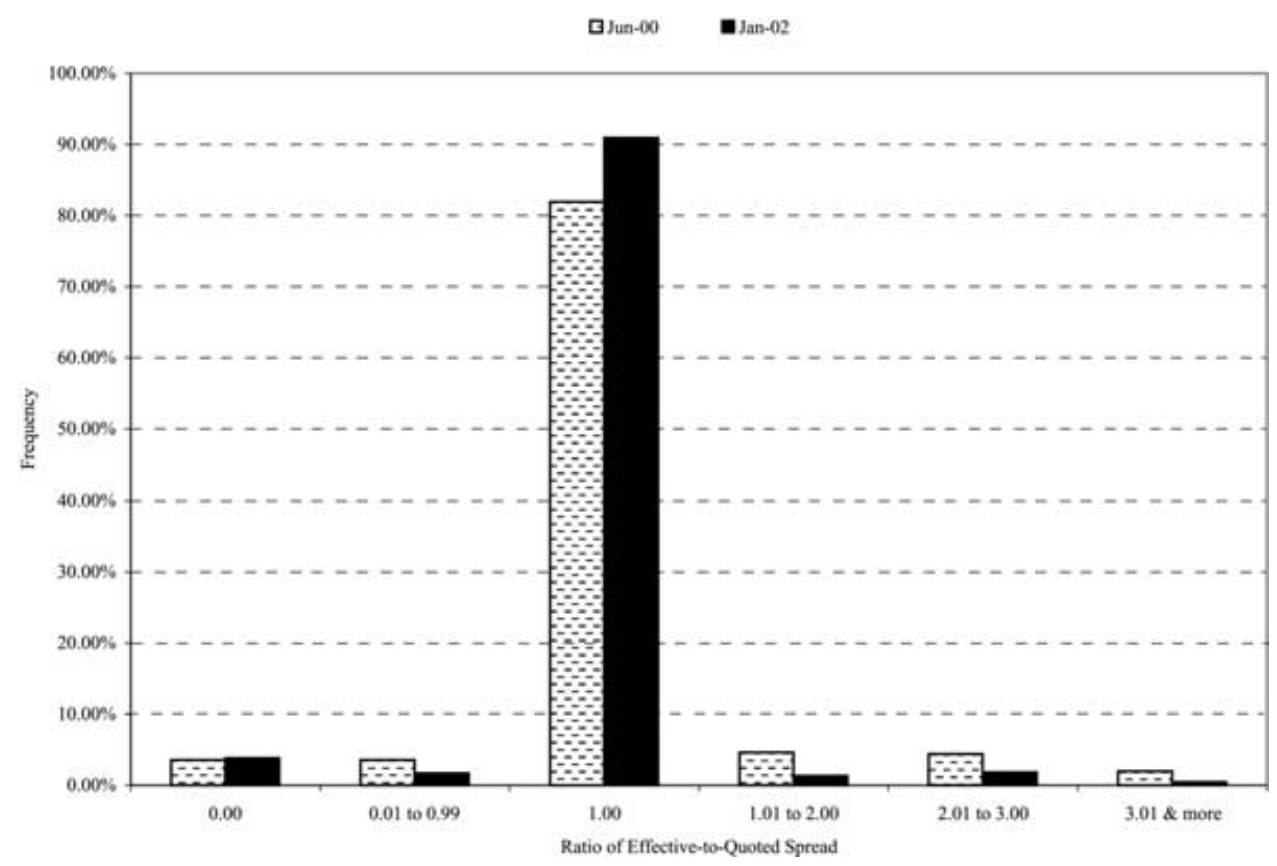

Figure 1. Distribution of relative execution costs. Our sample consists of 30 actively traded equity option classes listed on all four floor-based exchanges (Chicago Board Options Exchange (CBOE); American Stock Exchange (AMEX); Philadelphia Stock Exchange (PHLX); and Pacific Coast Exchange (PCX) in June 2000 and on all five exchanges (the four floor-based exchanges and the International Securities Exchange (ISE)) in January 2002. We use 21 days of trade and quote data each month. For each sample period, we examine the distribution of liquidity costs for trades executing when the National Best Offer, the lowest offer price across the exchanges, exceeds the National Best Bid, the highest bid price across the exchanges. For each trade, we measure relative execution costs as the ratio of the effective-to-quoted spread. The effective spread is twice the absolute distance between the trade price and the midpoint of the contemporaneous National Best Bid and Offer (NBBO) spread. The quoted spread is the distance between the National Best Offer price and the National Best Bid price for the particular option at the time of the trade. A ratio of zero represents a trade at the NBBO midpoint.

There is a shift toward more frequent trades at the relevant quoted price and fewer trades at worse-than-quoted prices. At-the-quote trades increased from 82 percent of the trades in June 2000 to 91 percent of the trades in January 2002. The 9 percentage point increase in the frequency of trades at the quote is the result of a 7 percentage point decrease in trades outside the quotes and a small decrease in the frequency of trades at prices between the NBBO spread midpoint and the relevant quoted price. ${ }^{22}$

${ }^{22}$ With the tighter quoted spreads in the second period, there are fewer chances for trades to occur at prices inside the quotes. From Table V, we see that the average quoted spread falls from about $\$ 0.20$ to less than $\$ 0.10$. With a tick size of $\$ 0.05$ ( $\$ 0.10)$ for options priced below (above) $\$ 3.00$, it is more difficult to trade inside the quote in January 2002 . 
To estimate how the cost of liquidity changes between the two sample periods, we consider the liquidity cost associated with initiating a package of 100 hypothetical 20-lot trades. To compute an average liquidity cost, we average the individual exchange's effective spreads for 2-to-50 contract category from Table V, based on the market share of trades from Table I. Because effective spreads approximate round-trip liquidity costs, we use one-half of the effective spread to estimate the liquidity costs associated with initiating our trade package. In June 2000, the liquidity cost of our hypothetical package of trades is $\$ 22,612$. In January 2002 , the liquidity cost of the 100 hypothetical trades falls 62 percent to $\$ 8,493$. We can also estimate the change in the economic cost of trade-throughs between the sample periods. The overall trade-through rate for 2-to-50 contract trades relative to the NBBO is 10.81 percent in June 2000 and 3.45 percent in January 2002. That implies eleven hypothetical trade-throughs in the first period and four in the second period. Replicating Table V for tradethroughs, we find the difference between the effective and quoted spreads falls from $\$ 0.3619$ in June 2000 to $\$ 0.1821$ in January 2002 (results not reported). Multiplying the cost per share times the number of share-equivalents trading gives a cost of $\$ 3,981(=11 \times \$ 0.3619 / 2 \times 20 \times 100)$ in June 2000 and $\$ 728(=4 \times \$ 0.1821 / 2 \times 20 \times 100)$ in January 2002 . Thus, opportunity costs imposed by trade-throughs fall by 82 percent for our hypothetical portfolio of trades.

\section{Time Series of Trade-through Rates and Spreads}

We have focused on the two end points of our data, June 2000 and January 2002. We also have incomplete data for the months between those sample months. Did the change in equity option market quality occur gradually during the 18 months between our sample periods or were there particular events that appear to cause discrete changes in market quality during those 18 months? In Figure 2, we report automatic execution trade-through rates and quoted and effective spreads for a week in each month for which we have data. We select the first Monday of each month and select the first available Tuesday, Wednesday, Thursday, and Friday of the month following that first Monday in order to control for any day-of-the-week effects that might exist in the data. ${ }^{23}$ With the exception of a sharp spike in the trade-through rate in January 2001 and some natural randomness, the decrease in the trade-through rate and spreads appears to be gradual throughout the 18-month period. ${ }^{24}$ This suggests that there are no watershed events that pushed the equity option market toward

\footnotetext{
${ }^{23}$ In most cases, this results in using the first full calendar week of each month. Sometimes, because of holidays and/or missing data, we must take nonsequential days to complete the week. For example, we cannot follow our procedure in October 2001, where only 4 days of data during the month are available. In this case, we use all 4 days. In all other months, 5 days of data are used to compute the relevant statistics. A list of the exact days used in this analysis can be obtained from the authors upon request.

${ }^{24}$ January 2001 corresponds to the decimalization of listed equities (about one-half of our sample options).
} 


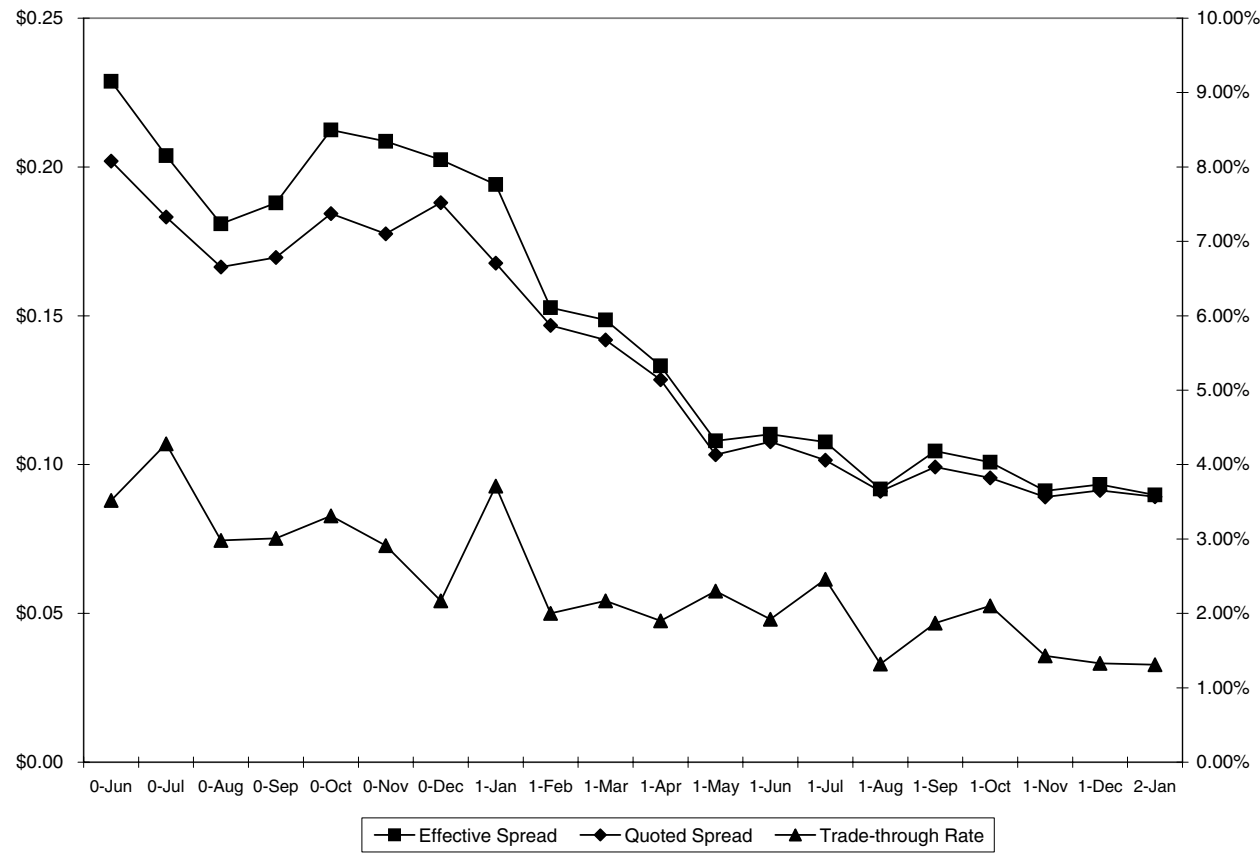

Figure 2. Time series of trade-through rates, quoted spreads, and effective spreads. Our sample consists of the automatic executions in 30 actively traded equity option classes listed on all four floor-based exchanges (Chicago Board Options Exchange, American Stock Exchange, Philadelphia Stock Exchange, and Pacific Coast Exchange) in June 2000 and on all five exchanges (the four floor-based exchanges and the International Securities Exchange) in January 2002. We use 5 days of trade and quote data each month (except for October 2001). For each week, we compute the trade-through rate relative to the National Best Bid and Offer (NBBO) prices. The National Best Offer (NBO) is the lowest offer price across the exchanges. The National Best Bid (NBB) is the highest bid price across the exchanges. The effective spread is twice the absolute distance between the trade price and the midpoint of the trade-time NBBO spread. The quoted spread is the distance between the NBO price and the NBB price for the particular option at the time of the trade. The quoted and effective spread are plotted with respect to the left vertical axis. The trade-through rates are plotted with respect to the right vertical axis.

more efficiency. Instead, it appears to have gradually evolved to the quality we document in January 2002.

Thus far, we have examined liquidity costs in a univariate setting. The fact that different exchanges report different trade-time quoted spreads suggests that the order flow is not identical among the exchanges. In order to determine whether the differences in execution quality persist after we control for factors that extant research has shown influence effective spreads, we undertake a multivariate analysis of liquidity costs.

\section{Multivariate Analysis of Effective Spreads}

Our multivariate analysis of execution quality focuses on the effective spread because we believe it is preferred to the trade-through rate as a comprehensive 
execution-quality measure. We use ordinary least squares with the White (1980) correction for heteroskedasticity to examine the determinants of executionprice quality for each trade. Because we have so many observations (over onehalf million trades in each sample period), we examine each sample day separately. Specifically, we estimate the following equation:

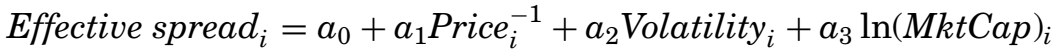

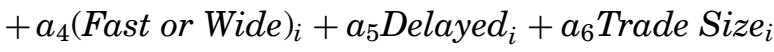

$$
\begin{aligned}
& +a_{7} A M E X_{i}+a_{8} P_{H L X_{i}}+a_{9} P C X_{i}+a_{10} I S E_{i}+e_{i} .
\end{aligned}
$$

Because trades represent only one side of a round-trip trade, we measure the dependent variable, effective spread, as twice the absolute difference between trade $i$ 's execution price and the midpoint of the execution-time $\mathrm{NBBO}^{25} \mathrm{We}$ use the difference from the variable mean rather than the level of each of the continuous variables in this regression. Using de-meaned control variables allows us to interpret the coefficient on the exchange binary variables as the conditional mean cost of liquidity for an "average" trade.

Equation (1) contains four variables found in most empirical work explaining spreads, two variables unique to the option market, and exchange-specific binary variables to detect differences in execution quality across market centers. We include the inverse of the execution-time NBBO midpoint as a control variable because extant work (e.g., Harris (1994)) shows that spreads depend on price levels. Because the underlying stock's volatility is directly related to option's price volatility, we include a measure of stock volatility as an independent variable. We measure stock volatility as the average of the log difference of the daily high and low prices in the underlying stock during the month prior to each sample period. ${ }^{26}$ To capture the effect of informational asymmetries and liquidity in the equity market on option trades, we include the natural log of the underlying stock's market capitalization (MktCap) as of the end of trading the day before the beginning of each sample period as a control variable.

The Fast-or-Wide binary variable equals 1 if quotes on the market with the trade are indicative (i.e., are "fast market" quotes) or if the quoted spread exceeds the guideline spread and equals 0 otherwise. To control for differences in the estimation error due to differences in trade-reporting speed, we include a binary variable for trades reported with delay. Theoretical predictions in Easley and O'Hara (1987) suggest a positive correlation between liquidity cost and trade size, so we also include trade size as a control variable.

Finally, we include separate binary variables for each exchange that indicate whether the execution occurred (value equals 1 ) or did not occur (value equals 0 )

\footnotetext{
${ }^{25} \mathrm{As}$ is the case in our univariate analysis of execution quality, we exclude trades executing in crossed markets from our multivariate analysis because our data make it difficult to evaluate execution quality in crossed markets.

${ }^{26}$ Using a more traditional measure of price volatility, the daily standard deviation of stock returns, produces similar conclusions. Our alternative measure provides a better fit with the data.
} 
on that exchange. We have separate binary variables for the AMEX, the PHLX, the PCX, and for the second sample period, the ISE. The coefficient estimates on the exchange binary variables provide estimates of how the indicated exchange's liquidity cost differs from the CBOE's liquidity cost, controlling for the other explanatory variables.

We expect trade $i$ 's effective spread to be increasing in the volatility of the underlying stock price and in trade size and decreasing in the market capitalization of the underlying stock and in the inverse of price. We also expect the effective spread to be higher when the executing market has either fast-market or wide quotes, because both actions are taken when market conditions make it difficult to provide a firm quote. Trades reported with delays are likely to exhibit poorer execution quality as we measure it (either because the execution quality really is poor or because we have incorrectly matched quoted prices to the trade price). Based on our univariate analysis, we expect effective spreads to be highest on the CBOE and the PCX.

Table VI characterizes the coefficient estimates in each sample period. Estimates of the coefficients on the inverse price are significantly negative at the 0.001 level for each day in both sample periods. Liquidity costs for options on volatile underlying stocks are significantly higher in June 2000 and significantly lower in January 2002. ${ }^{27}$ Estimates of the coefficients on the natural $\log$ of market capitalization are significantly negative at the 0.001 level for the majority of sample days. We find no significant correlation between trade size and effective spreads.

Focusing on the variables directly related to the equity option market, we find that the effective spread a round-trip trade pays increases by a statistically significant $\$ 0.2810$ per contract when the executing venue's quotes are marked FAST or when the quoted spread is wider than exchange guidelines during June 2000 and $\$ 0.0854$ in January 2002 . This suggests that an exchange's execution quality is worse when the exchange's quotes are only indicative. On a roundtrip basis, trades reported late have an effective spread that averages $\$ 0.1280$ per contract more than manual executions during June 2000 and $\$ 0.0456$ more in January 2002. (We cannot determine whether this wider spread is due to mismatching trades and quotes with our data.)

In June 2000, the negative coefficient estimates on the exchange dummies suggest that, after controlling for order flow characteristics and market conditions, on most sample days the PHLX and PCX charge a lower effective spread than does the CBOE. Pairwise Wilcoxon rank sum tests of differences in the daily median coefficient estimates of effective spread show that the CBOE charges the highest effective spread in June 2000 and the PHLX charges the

\footnotetext{
${ }^{27}$ This result might be an artifact of our methodology. We use the same volatility estimate (from the calendar month prior to each sample month) for all 21 daily regressions in each sample period, which means that the 21 regressions are not independent assessments of the effect of volatility on effective spreads. Other authors (e.g., DeFontnouvelle, Fishe, and Harris (2002), and Mayhew (2002)) fail to find a robust relation between bid-ask spreads and volatility estimates. We thank the referee for making this point.
} 


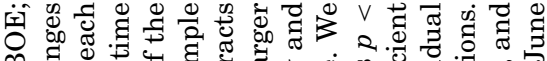
응 क्ष

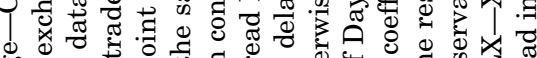
o. o o o o สี

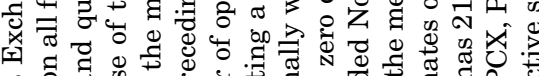

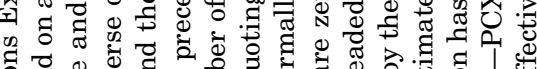

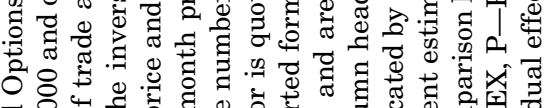
o 웡

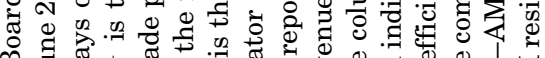

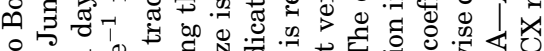

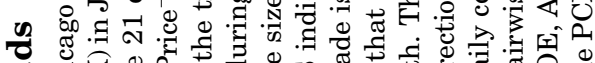

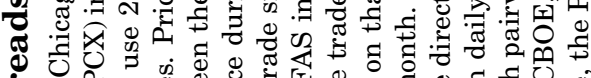
की की

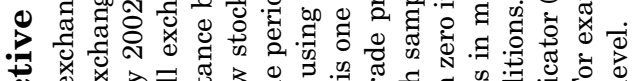

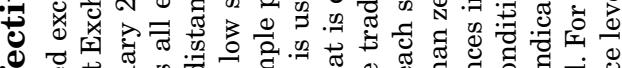

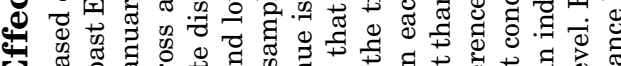

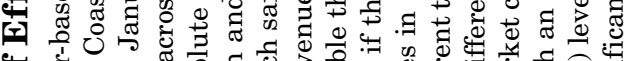

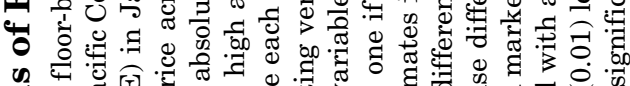

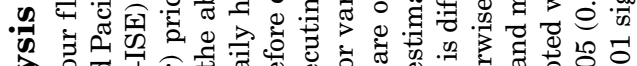
全

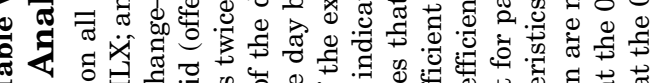
o 일 Q

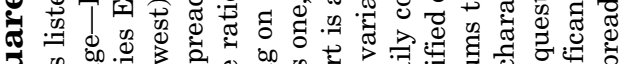

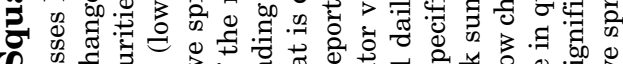
⿰亻 票 ơ

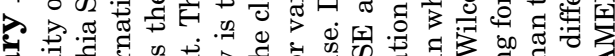

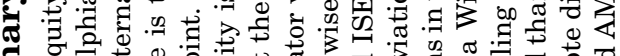

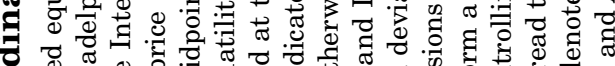

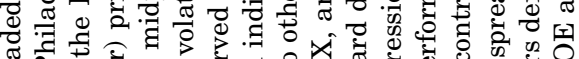

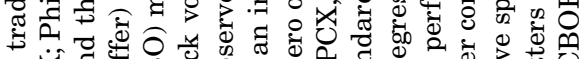

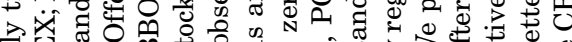

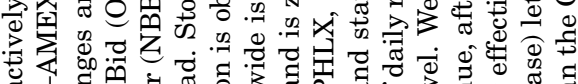
क

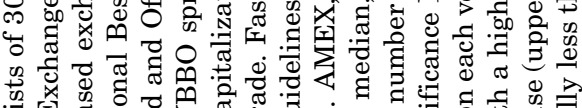
量 今。 语 졔

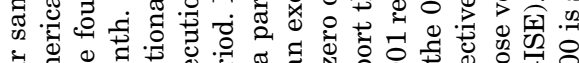

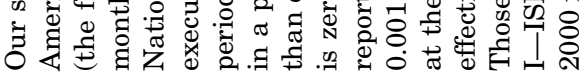

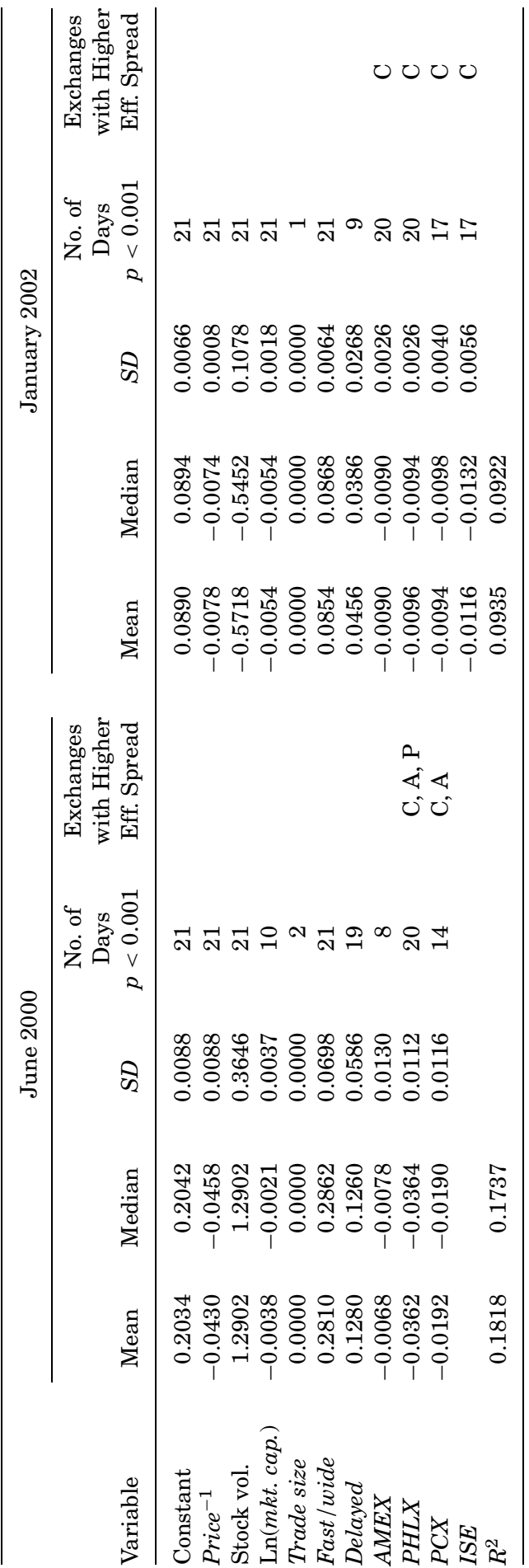


lowest. Our univariate analysis of execution quality (Tables IV and V) suggests that the differences in execution quality among exchanges diminished between the sample periods. We find similar evidence in the multivariate setting. The CBOE still charges a significantly higher effective spread than every other venue; however, there are no statistical differences between the effective spreads on the other four venues. Also the size of the differences in effective spread in 2002 between the CBOE and the other venues is either statistically smaller (PCX and PHLX) or statistically the same (AMEX) as in 2000. These results are consistent with increased interexchange competition and pressure on brokers to achieve best execution.

\section{E. Summary}

A national market system should produce economically efficient transactions and it should enable brokers to obtain "best execution" for their clients. We find that trade-through rates fall to levels in January 2002 that are no worse than trade-through rates for listed equities. We also document substantial reductions in quoted and effective spreads between June 2000 and January 2002, suggesting that execution quality has improved. Although we find some crosssectional variation in effective spreads across trading venues in both sample periods, the dispersion is reduced in January 2002. Simple univariate analyses suggest that effective spreads on the CBOE tend to be larger than effective spreads elsewhere. This result is confirmed in a regression framework where we control for other variables related to liquidity costs. All else being equal, these results suggest that some brokers are not fulfilling their fiduciary responsibility to obtain best execution for their clients. In the earlier sample period, this failure might have been attributable to a lack of relevant data to guide order routing decisions. Indeed, in June 2000 brokers relied on historical market share and/or payment for order flow when making order routing decisions. ${ }^{28}$ Although every exchange had some members who paid for order flow in January 2002, brokers had greater access to execution quality statistics then than they did in June 2000. This makes it more difficult for brokers to use a lack of market information to rationalize the decision to route orders to venues with higher liquidity costs.

\section{Conclusion}

We wish to determine whether a market with relatively little regulation historically, the equity option market, evolved toward a national market system following the increased competition associated with the onset of intense multiple listing in August 1999 and the introduction of the International Securities Exchange in May 2000. Based partially on an analysis of market data generated in June 2000, the SEC determined that mandated linkage is necessary to create a national market system for equity options. Given the potential costs

${ }^{28}$ See SEC (2000a) for a more complete description of the order routing environment in 2000. 
associated with linkage and the possibility that the current trading environment has moved toward a national market, a more recent analysis is necessary to quantify the potential benefits of government action. We use data from June 2000 and January 2002 to evaluate if changes in the economic efficiency and quality of executions in the equity option market appear to have reduced the need for formal linkage.

Examining option market quotes, we find evidence of dramatically improved market quality during the 18 months separating our two sample periods. Because crossed quotes (bid price exceeds offer price) suggest apparent arbitrage opportunities and/or nonfirm quotes, we examine these situations. There are nearly 70,000 instances of crossed quotes for our 30 sample option classes in June 2000 and the average option class has crossed quotes 93.6 seconds of each trading day. By January 2002, there are fewer than 10,000 cases when quotes cross and the average time in crossed markets falls to 14.4 seconds a day. The 85 percent reduction in the number of apparent arbitrage opportunities, combined with a slight decrease in the dollar amount by which quotes cross, results in a 90 percent decline in apparent potential profits from such arbitrage activity between our sample periods. We interpret these results as suggestive of a market evolving toward a national market system with little additional regulation (albeit with the threat of additional regulation).

Violations of price priority should occur seldom (if ever) in a national market system. Although prevalent in June 2000, trade-throughs decline precipitously by January 2002 . When execution-time quotes are used to evaluate execution prices, the trade-through rate for our sample falls from 11.09 percent to 3.74 percent. Using a conservative quote benchmark, we find that less than 1 percent of automatically executed trades fill at seemingly inferior prices in January 2002. The January 2002 trade-through rates are no higher than trade-through rates in the market for listed equities under comparable tick-size regimes, suggesting that the potential gain from additional government intervention in the equity option market might be small unless the market for equity options differs in fundamental ways from the market for equities.

We use effective spreads to evaluate execution quality across exchanges and across sample periods. Perhaps because of the marginal decrease in tick size, increased competition, heightened broker and investor awareness, and additional regulatory attention, effective spreads fall by over 60 percent from June 2000 to January 2002. Multivariate analyses suggest there are significant acrossexchange differences in effective spreads in June 2000, but that these differences largely dissipate by January 2002. In a national market system, the information brokers need to make informed order routing decisions is readily available. Although finding that effective spreads are similar across exchanges is consistent with the claim that the marginal broker makes informed order routing decisions, our results do not necessarily imply that some brokers lack the information necessary to obtain best execution. Even if brokers are aware of the relevant execution quality information, we might find across exchange differences in effective spreads if brokers maximize multiple dimensions of execution quality or if they ignore their fiduciary responsibility to obtain best 
execution (perhaps because of payment for order flow). We should note the limitations of trade and quote data. Without audit-trail order data, we cannot distinguish customer trades from proprietary trades; we cannot distinguish market order executions from limit order executions; and we cannot precisely match trade prices with quoted prices.

As envisioned by Congress, a national market system facilitates economically efficient transactions and allows brokers to obtain "best execution" for their customers. If Congress expects strict compliance with its national market system objectives, our results suggest that the equity option market falls short of meeting these objectives. However, extant research suggests that the listed-equity market, a market with linkage, firm quotes, rules prohibiting trade-throughs, and rules requiring the disclosure of execution quality statistics on a timely basis also falls short of this interpretation of national market system objectives. If the listed equity market approximates a national market system, our results suggest that the equity option market's transformation into a national market system might be nearly complete. More generally, our results suggest that the forces of competition, improved technology, and the threat of increased regulation may achieve regulatory objectives without imposing additional costs.

\section{REFERENCES}

De Fontnouvelle, Patrick, Raymond Fishe, and Jeffrey Harris, 2002, The behavior of bid-ask spreads and volume in options markets during the listings competition in 1999, Working paper, University of Delaware.

Easley, David, and Maureen O'Hara, 1987, Price, trade size and information in security markets, Journal of Financial Economics 19, 69-90.

Hansch, Oliver, and Frank Hatheway, 2001, Measuring execution quality in the listed option market, Working paper, Pennsylvania State University.

Harris, Lawrence, 1994, Minimum price variations, discrete bid-ask spreads, and quotation sizes, Review of Financial Studies 7, 148-179.

Macey, Jonathan, and Maureen O'Hara, 1997, The law and economics of best execution, Journal of Financial Intermediation 6, 188-223.

Mayhew, Stewart, 2002, Competition, market structure, and bid-ask spreads in stock option markets, Journal of Finance 57, 931-958.

Neal, Robert, 1992, A comparison of transaction costs between competitive market maker and specialist market structures, Journal of Business 65, 317-334.

Peterson, Mark, and Erik Sirri, 2002, Evaluation of the biases in execution cost estimation using trade and quote data, Journal of Financial Markets 6, 259-280.

Restated ITS Plan, 1997.

Securities and Exchange Commission, Release No. 34-16701, 1980.

Securities and Exchange Commission, Release No. 34-42029, Order directing options exchanges to submit an intermarket linkage plan pursuant to Section 11A(a) (3) (B) of the Securities Exchange Act of 1934, 1999.

Securities and Exchange Commission, Special Study: Payment for Order Flow and Internalization in the Options Markets," 2000a.

Securities and Exchange Commission, Release No. 34-43086, Order approving option market intermarket linkage plan submitted by the American Stock Exchange LLC, the Chicago Board Options Exchange, Inc., and the International Stock Exchange, LLC, 2000b.

Securities and Exchange Commission, Release No. 34-43591, Firm quote and trade-through disclosure rules for options, 2000 c. 
Securities and Exchange Commission, Release No. 34-42456, Notice of filing of proposed option market linkage plans by the American Stock Exchange, Chicago Board Options Exchange, Pacific Exchange, and Philadelphia Exchange, 2000d.

Securities and Exchange Commission, Release No. 34-43085, Proposed rule: Firm quote and tradethrough disclosure rules for options, 2000e.

Securities and Exchange Commission, Release No. 34-43591, Firm quote and trade-through disclosure rules for options, 2001.

Securities and Exchange Commission, Release No. 34-43621, Options price reporting authority, 2001.

Securities and Exchange Commission, Report on the Practice of Preferencing, 1997.

Stoll, Hans, 2001, Market fragmentation, Financial Analysts' Journal 56, 16-20.

Wall Street Journal, 1999a, Options report: Exchanges, on one Dell swoop from CBOE, cast aside their custom of exclusive listings, August 19, C20.

Wall Street Journal, 1999b, Options report: All appears fair in love and options trading as CBOE, Amex, Philadelphia war over Dell, August 24, C26.

Wang, Elizabeth, 2000, Competition among exchanges: Does multiple listing affect trading costs on options markets?, Working paper, University of Chicago.

White, Halbert, 1980, A heteroskedasticity-consistent covariance matrix estimator and a direct test for heteroskedasticity, Econometrica 48, 817-838. 
Copyright of Journal of Finance is the property of Blackwell Publishing Limited and its content may not be copied or emailed to multiple sites or posted to a listserv without the copyright holder's express written permission. However, users may print, download, or email articles for individual use. 